\title{
Advancing research in Sri Lanka
}

The article on "A policy for research in Sri Lanka" appearing in the September 2006 issue of the Journal of the National Science Foundation must be taken serious note of by policy makers working towards the economic development of the country. The article analyses the Sri Lankan research output during 1996-2004 based on information collected in three surveys conducted in 1996, 2000 and 2004 by the National Science Foundation. Various indicators such as the number of researchers, number of research publications, patents and other outputs as well as national and international achievements by scientists have been considered in this analysis. One of the key findings of the study points to the fact that the national R\&D effort has remained at a standstill, with no strengthening or discernible improvement in the national capability for research over a period of three decades or more.

One cause attributed for this poor state of the S\&T capability of the country is the appallingly low Government Expenditure on R\&D (GERD) during the period since the country gained independence. The article calls for long-term funding not subject to vagaries of short term partisan-bound politics based on a two component funding system including an institutional subsistence component and a research programme component. Such a system if put into operation will no doubt enhance the research capability of the R\&D institutions.

The article also refers to the human resources lost to the country due to scientific migration. It is the more qualified mid-career scientists with experience that get caught in the net spread by the developed countries. This leaves a void at senior level which affects the training of young scientists who will provide future leadership for the country's research effort. The article ends with a note that we as a nation must try to retain our quality scientists and not sacrifice them.

Another barrier for advancing research in Sri Lanka has been an archaic regulation which prevents the free movement of public sector scientists. These rules made originally in the sixties have remained static while most other restrictions involving foreign travel imposed during that time have been removed under the free economic policies. These rules affect scientists needing to attend scientific meetings overseas - seminars, conferences, workshops - to present scientific papers based on their research findings and for furthering their knowledge. Any control on free movement of scientists also contributes to their migration. Rules on overseas travel by scientists need to be amended leaving the authority for approval in the hands of the management of respective institutions.

When considering the issue of quality of human resources for research, we in Sri Lanka are faced with a situation, perhaps peculiar to our country. The admission to professional courses such as medicine and engineering is based on high performance at the GCE (Advanced Level) examination. This leads to students with higher grades pursuing professional careers which have the potential for higher incomes and recognition by society and also the government. The result is that, in general, the better performers at the GCE (A/L) examination do not pursue scientific careers. A concerted and practical effort has to be made to attract the best brains to pursue basic scientific careers, and only then the country will be in a position to accelerate the progress in research.

Another recommendation made in the article for boosting the country's research is to adopt a goal-oriented strategy. While agreeing with this recommendation, cognisance must also be taken of instances where research in basic sciences has led to the development of products that have impacted the global economy. Two such cases are worth mentioning here. One was the Nobel Prize winning discovery of the transistor 60 years ago which resulted from studies on electrical properties of semi-conductors. It revolutionalised the entire electronics industry enabling it to evolve into the modern ICT industry. The other is the recent Nobel Prize winning discovery of the Giant Magnetoresistance phenomenon which resulted from studies on electrical properties of nano-layers of different material. This led to the development of high density data storage devices incorporated in today's notebook computers and various 
other digital devices. Both these discoveries were made while conducting research in Physics Laboratories with no goals in mind of their potential applications. The need for a balance between basic and goal-oriented research is therefore evident.

There are other restrictions imposed on research institutions that prevent their smooth functioning. One is the lack of freedom to recruit staff, even after the cadre and funds have been approved. This prevents meeting targets in time bound research. Another is the lack of freedom to purchase sophisticated research equipment without referring the individual cases to higher authorities, even after the necessary funds have been voted. The government authorities need to recognize the special needs of R\&D institutions in respect of personnel, equipment and other resources which are necessary to achieve the expected outputs, within the allocated time frame. Without these basic pre-requisites, no country can forge ahead in today's highly competitive S\&T arena.

Nalini Ratnasiri 